\title{
PREDIKSI KEMACETAN ANGSURAN LEASING MOTOR MENGGUNAKAN ALGORITMA BACKPRPAGATION NEURAL NETWORK BERBASIS PARTICLE SWARM OPTOMIZATION
}

\author{
Aulia Rizky Muhammad Hendrik Noor Asegaff \\ Fakultas Teknologi Informasi \\ Universitas Islam Kalimantan Muhammad Arsyad Al Banjari Banjarmasin \\ aulia.rizky.m.h.n.a@gmail.com
}

\begin{abstract}
ABSTRAK
Sekarang ini permintaan akan kendaraan bermotor sangat banyak ditambah lagi dengan kemudahan pada proses jual-belinya, sehingga mendorong pertumbuhan perusahaan leasing. Perusahaan leasing memberikan kemudahan kepada masyarakat agar dengan mudah mendapatkan kendaraan bermotor seperti dengan uang muka yang ringan, angsuran yang rendah dan tenor yang panjang. Namun, hal itu dapat menimbulkan resiko angsuran macet yang mengkhawatirkan bagi perusahaan itu sendiri. Penanggulangan dan pembatasan angsuran macet belum menemukan cara yang paling sesuai karena selama ini analisa pengajuan kredit dilakukan hanya pendekatan personal dengan mengisi Form Data Konsumen dan survey lapangan.

Algoritma klasifikasi data mining dengan model algoritma Backpropagation Neural Network menunjukan bahwa model ini mempunyai tingkat akurasi yang baik serta dapat dioptimasi Particle Swarm Optimization (PSO) dengan melakukan pengujian secara terukur melalui parameter training cycle, learning rate dan momentum, sehingga mendapatkan hasil accuracy, precision, recall dan AUC dengan bantuan Rapi Miner. Hasilnya setelah dilakukan pengujian dengan menggunakan data konsumen dan data rekap pembayaran (collection), pada BPNN mendapatkan parameter terbaik pada nilai 200 untuk training cycle, 0.1 pada learning rate dan 0.1 pada momentum menghasilkan accuracy $75.11 \%$, precision $77.55 \%$, recall $84.89 \%$ dan AUC 0.772. Sedangkan pada BPNN-PSO menghasilkan accuracy $76.98 \%$, precision 77.96 , recall $87.88 \%$ dan AUC 0.814 .
Kata
kunci
:
angsuran,
leasing,
BPNN-PSO 


\section{PENDAHULUAN}

Kemudahan dalam mendapatkan pembiayaan kendaraan bermotor dari leasing dapat menimbulkan menimbulkan resiko angsuran macet yang cukup besar dari leasing itu sendiri. Berdasarkan penelitian mengenai analisa resiko kredit memberikan kesimpulan bahwa faktor yang mempengaruhi resiko angsuran macet dari sisi konsumen adalah overdue, down payment, tenor, pendapatan kosumen, moral dan morale hazard. Penelitian lain memberikan kesimpulan bahwa untuk variabel pendapatan (salary), domicile, effective rate, tenor, dan net $d p$ amount menjadi variabel yang berpengaruh signifikan terhadap status kredit konsumen. Sementara untuk variabel gender, marital, age, dan principal amount tidak berpengaruh signifikan terhadap status kredit konsumen

Masalah utama yang dihadapi dalam backpropagation adalah lamanya iterasi yang harus dilakukan. backpropagation tidak dapat memberikan kepastian tentang berapa epoch yang harus dilalui untuk mencapai kondisi yang diinginkan. Salah satu algoritma optimasi global yang berkembang saat ini adalah Particle Swarm Optimization (PSO). Teknik ini diinisialisasi dari sekumpulan nilai awal pada sebuah populasi, kemudian mencari nilai yang paling optimal dengan memperbaharui nilai tersebut pada setiap langkahnya. Pada penelitian ini digunakan PSO sebagai algoritma pelatihan.

\section{RUMUSAN MASALAH}

Berdasarkan permasalahan tersebut diatas maka dapat disimpulkan bahwa algoritma Backpropagation
Neural Network berbasis Particle Swarm Optimization dapat dipakai dalam pengkalisifikasian dan pengelompokan data.. Sedangkan pertanyaan penelitian (research questions) pada penelitian ini adalah: "Bagaimanakah algoritma Backpropagation Neural Network berbasis Particle Swarm Optimization dalam memprediksi kemacetan angsuran leasing ?"

\section{TUJUAN PENELITIAN}

Berdasarkan latar belakang dan rumusan masalah di atas, maka penelitian ini bertujuan :

1. Menerapkan Particle
Optimization (PSO)
Backpropagation
Network (BPNN) dengan
menguji coba dataset untuk
mencari parameter terbaik dari

2. Menentukan pola kemacetan yang dihasilkan untuk menentukan kelancaran angsuran dimasa yang akan datang.

3. Tercapainya tingkat akurasi data dari Aging atau data tarikan perusahaan leasing dengan metode penerapan $P S O$ pada $B P N N$.

\section{METODE PENELITIAN}

Jenis penelitian yang digunakan dalam penelitian ini adalah metode penelitian eksperimen. Penelitian eksperimen ini menggunakan penerapan Backpropagation dan di optimasikan dengan Particle Swarm Optimization (PSO). Dalam penelitian ini mampu memberikan dan mempermudah Leasing untuk mengambil keputusan dalam memanfatkan dari prediksi kemacetan angsuran. Tahapan untuk 
Metode penelitian eksperimen sebagai berikut :

a. Pengumpulan data

b. Pengolahan data awal

c. Eksperimen dan pengujian (method test and Experiment)

d. Evaluasi dan validasi hasil (Result Evaluation and Validation).

\section{Pengumpulan Data}

Data yang digunakan dalam penelitian ini adalah data sekunder yang diperoleh secara langsung dari PT. Bess Finance yang merupakan data rahasia perusahaan. Varibel data yang diambil antara lain Nomor Kontrak, repeat order, angsuran, pekerjaan, penghasilan, usia, status, kw_tunggak.

\section{Pengolahan Data Awal (Data Preprocessing)}

Data yang digunakan dalam penelitian ini adalah data sekunder yang diperoleh secara langsung dari PT. Bess Finance yang merupakan data rahasia perusahaan. Dari dari dataset tersebut masih berupa data yang harus diolah terlebih dahulu, kemudian dilakukan penyeleksian data, data dimodifikasi sesuai kebutuhan dan ditransformasikan kedalam bentuk yang diinginkan sehingga dapat dilakukan persiapan dalam pembuatan model.

\section{Eksperimen dan Pengujian}

Pelatihan dilakukan dengan data

PT. Bess Finance, untuk pengujian awal dilakukan menggunakan rapidminer, yang mana memasukkan data menggunakan file berformat excel untuk melakukan uji model menggunakan BPNN berbasis PSO.
4. Evaluasi Hasil dan Validasi

Evaluasi terhadap model yang terbentuk akan dilakukan dengan pengukuran accuracy, precision, recall, dan AUC. Proses evaluasi akan dilakukan dengan menggunakan cross validation. Sehingga model yang terbentuk dapat langsung diuji dengan data yang secara acak dipisahkan dengan 10 folds cross validation.

Dengan confusion matrix, nilai akurasi dari model akan dibandingkan antara model yang tebentuk dengan algoritma Backpropogation Neural Network dan algoritma Backpropogation Neural Network yang sudah dioptimasi dengan Particle Swarm Optimization.

\section{ANALISA HASIL DAN PEMBAHASAN}

1. Evaluasi dan Pengujian Model

Hasil dari pengujian model yang dilakukan pada bab III adalah predikasi kemacetan angsuran leasing motor dengan algoritma backpropogation neural network dan klasifikasi backpropogation neural network berbasis particle swarm optimization untuk menetukan nilai accuracy, dan AUC.

Dalam pengujian model yang dilakukan pada prediksi kemacetan angsuran leasing motor dengan algoritma backpropogation neural network parameter yang digunakan Nomor kontrak, repeat order, tenor, angsuran, pekerjaan, penghasilan, usia, status, dan kw tunggak sebagai target.

Untuk pengujian menggunakan algoritma klasifikasi BPNN network berbasis PSO parameter yang digunakan sama dalam pengujian pada algoritma BPNN, akan tetapi tenor, penghasilan, usia dan status 
adalah parameter yang sangat mempengaruhi dalam penilai akurasi.

\section{Hasil Pengujian Menggunakan algoritma BPNN}

Algoritma yang akan diuji dalam penelitian ini adalah BPNN dengan menggunakan beberapa parameter, yaitu iterasi (training cycles), learning rate, momentum,accuracy dan $A U C$. Dalam penelitian ini, digunakan 5 konfigurasi parameter. Nilai dari parameter - parameter ini ditentukan secara coba-coba. Kemudian diukur confusion matrix.

Eksperimen ini dimulai dari penentuan nilai training cycles, dalam penelitian ini nilai training cycles ditentukan dengan cara melakukan uji coba memasukan nilai range 100 sampai 1000 untuk training cycles, serta nilai 0.1 untuk learning rate dan 0.1 untuk momentum. Berikut ini adalah hasil dari percobaan yang telah dilakukan untuk penentuan nilai training cycles:

Tabel 1 Parameter yang digunakan training cycles pada BPNN

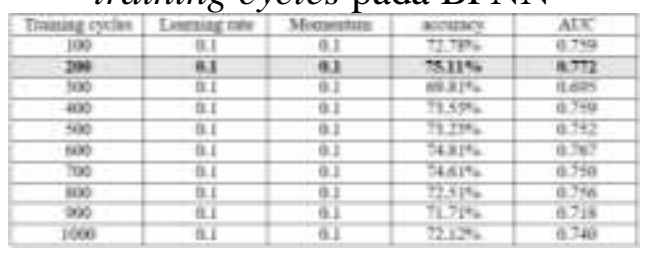

Berdasarkan hasil pecobaan di atas, maka parameter BPNN dipilih nilai 200 untuk training cycles, 0.1 untuk learning rate, dan nilai 0.1 untuk momentum. Nilai 600 ini selanjutnya untuk percobaan dalam menentukan nilai learning rate.

Nilai learning rate ditentukan dengan cara melakukan dengan uji coba memasukkan nilai dengan range 0.1 sampai dengan 0.9 . Nilai training cycles dipilih dari percobaan sebelumnya yaitu 200, sedangkan 0.1 digunakan untuk nilai momentum. Berikut ini adalah hasil dari percobaan yang telah dilakukan untuk penentuan nilai learning rate:

Tabel 2 Parameter yang digunakan learning rate pada BPNN

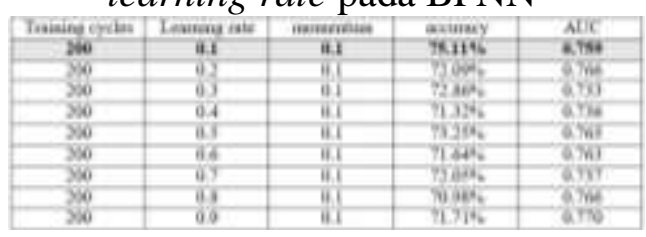

Nilai learning rate dipilih berdasarkan nilai accuracydan nilai $A U C$ terbesar yang dihasilkan. Berdasarkan hasil percobaan di atas, dipilih nilai learning rate sebesar 0.1 . Nilai 0.1 ini selanjutnya dipakai untuk percobaan dalam menentukan nilai momentum.

Nilai momentum ditentukan dengan cara melakukan dengan uji coba memasukkan nilai dengan range 0.1 sampai dengan 0.9. Nilai training cycles 200 dan learning rate 0.1 dipilih berdasarkan percobaan sebelumnya. Berikut ini adalah hasil dari percobaan yang telah dilakukan untuk penentuan nilai momentum:

Tabel 3 Parameter yang digunakan momentum pada BPNN

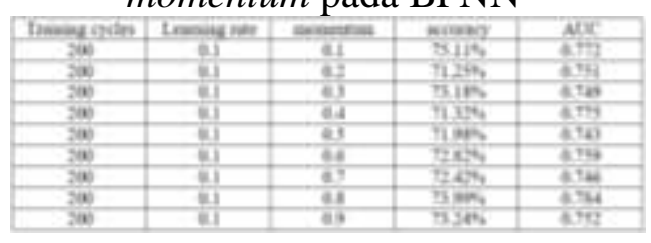

Berdasarkan hasil percobaan di atas, maka untuk parameter neural network dipilih nilai 200 untuk training cycles, 0.1 untuk learning rate dan 0.1 untuk momentum.

Hasil dari uji coba yang dilakukan yaitu untuk menghasilkan 
accuracy dan nilai AUC(Area Under Curve).

Tabel 4 Confusion Matrix BPNN

\begin{tabular}{|c|c|c|}
\hline True & Macet & Lancar \\
\hline Macet & 56 & 20 \\
\hline Lancar & 41 & 145 \\
\hline
\end{tabular}

Tabel 5 Pengujian Algoritma BPNN

\begin{tabular}{|c|c|}
\hline Name & Persentase \\
\hline Accuracy & $75.18 \%$ \\
\hline Precision & $77.55 \%$ \\
\hline Recall & $84.89 \%$ \\
\hline
\end{tabular}

Evaluasi menunjukan grafik ROC dengan nilai AUC(Area Under Curve) sebesar 0,772

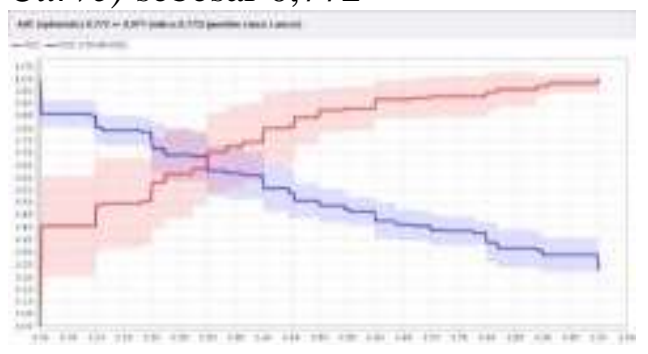

Gambar 1 AUC (Area Under Curve) BPNN

Pada gambar 1 garis berwarna merah merupakan curve ROC dengan nilai sebesar 0.772 termasuk klasifikasi dengan nilai yang baik, sedangkan garis berwarna biru merupakan kurva ambang (Thresholds).

\section{Hasil Pengujian Menggunakan algoritma BPNN berbasis PSO \\ PSO memiliki perbandingan} lebih atau bahkan pencarian kinerja lebih unggul untuk banyak masalah optimasi dengan lebih cepat dan tingkat konvergensi yang lebih stabil. Untuk menemukan solusi yang optimal, masing-masing partikel bergerak kearah posisi yang terbaik sebelumnya dan posisi terbaik secara global.

Eksperimen ini dimulai dari penentuan nilai training cycles, nilai training cycles ditentukan dengan cara melakukan uji coba memasukan nilai range 100 sampai 1000 untuk training cycles, serta nilai 0.1 untuk learning rate dan 0.1 untuk momentum. Berikut ini adalah hasil dari percobaan yang telah dilakukan untuk penentuan nilai training cycles, hasil dari uji coba yang dilakukan yaitu untuk menghasilkan accuracy dan nilai AUC(Area Under Curve).

Tabel 6 Parameter yang digunakan training cycles pada BPNN-PSO

\begin{tabular}{|c|c|c|c|c|}
\hline In aur Cyde & I canumy Jate & Mamananum & Accuasy & AUC \\
\hline 100 & aI & ei & $\pi 35$ & $0 \times 90$ \\
\hline $2 \infty$ & AI & $a .1$ & 76.95 & 0816 \\
\hline 300 & ai & 01 & 7650 & es15 \\
\hline 400 & a.1 & a.1 & 73.5 & 0541 \\
\hline 300 & 01 & eI & 2650 & o.s4 \\
\hline 600 & 6I & 0.1 & 10.75 & $0 \times 54$ \\
\hline 700 & O.I & a. & 20.75 & ONE \\
\hline 800 & 81 & e.1 & 745 & OSHI \\
\hline 500 & 01 & 0.1 & 86.2 & $0 \times 0$ \\
\hline 1000 & 61 & 0.1 & M91 & 0.533 \\
\hline
\end{tabular}

Berdasarkan hasil pecobaan di atas, maka parameter BPNN-PSO dipilih nilai 900 untuk training cycles, 0.1 untuk learning rate, dan nilai 0.1 untuk momentum karena sebagai nilai tertingginya.

Nilai learning rate ditentukan dengan cara melakukan dengan uji coba memasukkan nilai dengan range 0.1 sampai dengan 0.9 . Nilai training cycles dipilih dari percobaan BPNN sebelumnya yaitu 200, sedangkan 0.1 digunakan untuk nilai momentum. Berikut ini adalah hasil dari percobaan yang telah dilakukan untuk penentuan nilai learning rate:

Tabel 7 Parameter yang digunakan learning rate BPNN-PSO 


\begin{tabular}{|c|c|c|c|c|}
\hline Training Cycle & Lesming Rate & Morteunim & Accuracy & AUC \\
\hline 200 & of & a.1 & 76.98 & 0.79 \\
\hline 200 & 02 & 0.1 & 76.23 & 0.828 \\
\hline 200 & 05 & 0.1 & 78.49 & 0.831 \\
\hline 200 & 04 & 0.1 & 7736 & 0.846 \\
\hline 200 & 0.5 & 0.1 & 8236 & 0.896 \\
\hline 200 & 0.6 & 0.1 & $3 \pi \pi$ & ant7 \\
\hline 200 & 0.7 & 0.1 & 80.00 & 0.564 \\
\hline 200 & os & 0.1 & 7925 & 0.164 \\
\hline 200 & 09 & 0.1 & 81.66 & 0.871 \\
\hline
\end{tabular}

Nilai learning rate dipilih berdasarkan nilai accuracy dan nilai $A U C$ terbesar yang dihasilkan. Berdasarkan hasil percobaan di atas, dipilih nilai learning rate sebesar 0.6 karena sebagai nilai tertingginya.

Nilai momentum ditentukan dengan cara melakukan dengan uji coba memasukkan nilai dengan range 0.1 sampai dengan 0.9 . Nilai training cycles 200 dan learning rate 0.1 dipilih berdasarkan percobaan BPNN sebelumnya. Berikut ini adalah hasil dari percobaan yang telah dilakukan untuk penentuan nilai momentum:

Tabel 8 Parameter yang digunakan momentum BPNN-PSO

\begin{tabular}{|c|c|c|c|c|}
\hline Trainine Cycle & Leternins Rate & Mamentime & Acturacy & $A \cup C$ \\
\hline 200 & o.t & 0.1 & 7695 & asia \\
\hline 260 & 01 & 0.2 & 7736 & 0.551 \\
\hline 200 & Q.1 & 03 & 72.11 & 0.490 \\
\hline 200 & 21 & 04 & 7648 & a.s5u \\
\hline 200 & 01 & 0.5 & 79.73 & 0.140 \\
\hline 200 & et & 06 & $76 \%$ & 0.573 \\
\hline 200 & 01 & 07 & $\pi 74$ & 0.553 \\
\hline 200 & 0.1 & os & 72.71 & a.s? ? \\
\hline 200 & 01 & 09 & $10 \pi 3$ & 0.14 \\
\hline
\end{tabular}

Berdasarkan hasil percobaan di atas, maka untuk parameter neural network dipilih nilai 200 untuk training cycles, 0.1 untuk learning rate dan 0.9 untuk momentum sebagai nilai tertingginya.

Hasil dari uji coba yang dilakukan yaitu untuk menghasilkan accuracy dan nilai AUC(Area Under Curve).

Tabel 9 Confusion matrix BPNNPSO

\begin{tabular}{|c|c|c|}
\hline True & Macet & Lancar \\
\hline Macet & 59 & 20 \\
\hline
\end{tabular}

\begin{tabular}{|l|l|l|}
\hline Lancar & 41 & 145 \\
\hline
\end{tabular}

Tabel 10 Pengujian Algoritma BPNN berbasis PSO

\begin{tabular}{|c|c|}
\hline Name & Persentase \\
\hline Accuracy & $76.98 \%$ \\
\hline Precision & $77.96 \%$ \\
\hline Recall & $87.88 \%$ \\
\hline
\end{tabular}

Evaluasi menunjukan grafik ROC dengan nilai AUC(Area Under Curve) sebesar 0,814.

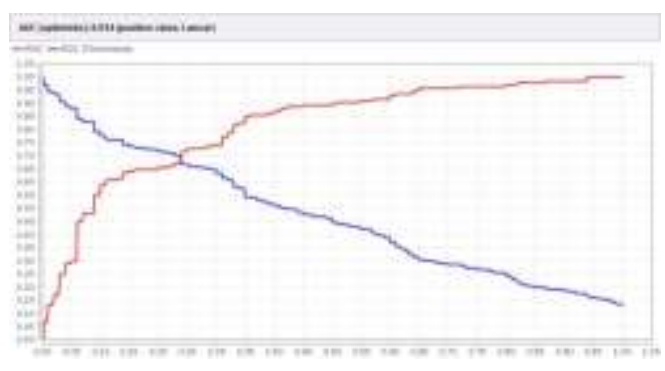

Gambar 2 AUC (Area Under Curve) BPNN berbasis PSO

Pada gambar 2 garis berwarna merah merupakan curve ROC dengan nilai sebesar 0,814 termasuk klasifikasi dengan nilai baik, sedangkan garis berwarna biru merupakan kurva ambang (Thresholds).

\section{Analisis Evaluasi dan Validasi Model}

Dalam pengujian model yang dilakukan pada prediksi kemacetan angsuran leasing motor dengan algoritma backpropogation neural network parameter yang digunakan Nomor kontrak, repeat order, tenor, angsuran, pekerjaan, penghasilan, usia, status, dan kw tunggak sebagai target. Untuk pengujian menggunakan algoritma klasifikasi BPNN berbasis PSO parameter yang digunakan sama dalam pengujian pada algoritma BPNN, Untuk 
pengujian menggunakan algoritma klasifikasi BPNN network berbasis PSO parameter yang digunakan sama dalam pengujian pada algoritma BPNN, akan tetapi tenor, penghasilan, usia dan status adalah parameter yang sangat mempengaruhi dalam penilai akurasi.

Dari hasil pengujian diatas, dengan dilakukan evaluasi baik secara confusion matrix maupun ROC curve ternyata terbukti bahwa pengujian yang dilakukan algoritma BPNN berbasis PSO memiliki nilai akurasi yang lebih tinggi dibanding hanya menggunakan algoritma prediksi BPNN yang terjadi pada parameter training Cycle 200, learning rate 0.1 dan momentum 0.1 . Nilai akurasi untuk model algoritma BPNN sebesar $75.11 \%$ dan nilai akurasi algoritma BPNN berbasis PSO sebesar $76.98 \%$ dengan selisih akurasi sebesar $1.87 \%$, dapat dilihat pada tabel 11 dibawah ini :

Tabel 11 Pengujian Algoritma BPNN dan BPNN berbasis PSO

\begin{tabular}{|c|c|c|}
\hline & Accuracy & AUC \\
\hline BPNN & $75.11 \%$ & 0.772 \\
\hline $\begin{array}{c}\text { BPNN } \\
\text { berbasis PSO }\end{array}$ & $76.98 \%$ & 0.814 \\
\hline
\end{tabular}

Untuk evaluasi menggunakan ROC curve sehingga menghasilkan nilai AUC untuk model algoritma BPNN menghasilkan 0.772 dengan nilai diagnosa cukup baik. Sedangkan algoritma BPNN berbasis PSO menghasilkan nilai 0.814 dengan nilai diagnosa lebih baik, dan selisih keduanya sebesar 0.042 .

Dengan demikian algoritma BPNN berbasis PSO memberikan solusi untuk permasalahan predikasi kemacetan angsuran motor.

\section{PENUTUP}

\section{Kesimpulan}

Hasil penelitian untuk nilai akurasi algoritma Backpropogation Neural Network (BPNN) senilai $75.11 \%$, sedangkan untuk nilai akurasi algoritma backpropogation neural network berbasis particle swarm optimization senilai $76.98 \%$. Sehingga selisih untuk nilai akurasi sebesar $1.87 \%$. Dan dievaluasi menggunakan ROC curve untuk keduanya yaitu, nilai AUC (Area Under Curve) berdasarkan ROC curve untuk algoritma sehingga menghasilakan nilai AUC untuk model algoritma Backpropogation Neural Network (BPNN) menghasilkan 0.772 dengan nilai diagnosa Good. Sedangkan algoritma Backpropogation Neural Network (BPNN) berbasis Particle Swarm Optimization (PSO) menghasilkan nilai 0.814 dengan nilai diagnosa Good, dan selisih keduanya sebesar 0.042 .

Hasil pengujian dari metode-metode tersebut menggunakan beberapa parameter agar didapatkan nilai terbaiknya. Parameter yang digunakan antara lain training cyrcle, learning rate, dan momentum. Dari pengujian didapatkan nilai parameter terbaik pada training cycle 200, learning rate 0.1 dan momentum 0.1 .

\section{Saran}

Berdasarkan proses pengujian dan kesimpulan yang telah dilakukan, maka ada beberapa saran dalam penelitian ini adalah :
a. Dapat dilakukan perbandingan dengan metode algoritma lain yang mendukung pengujian data yang ada sehingga bisa didapat tingkat akurasi yang lebih baik lagi. 
b. Dalam penelitian ini perlu menambah jumlah data yang lebih besar dan, untuk menghasil akurasi yang lebih akurat dan lebih tinggi yang akan didapatkan lebih baik lagi.

\section{DAFTAR PUSTAKA}

[1] Adi Sucipto, 2015. Prediksi Kredit Macet Melalui Perilaku Nasabah Pada Koperasi Simpan Pinjam dengan Menggunakan Metode Algoritma Klasifikasi C4.5. Jurnal DISROTEK, vol 6(1), pp. 75-87.

[2] Suwondo and Stefanus Santosa, 2014. Credit Scoring Menggunaan Metode Support Vector Mechine dengan Teknik Seleksi Atribut Berbasis Chi Square Statistic dan Particle Swarm Optimization. Jurnal Teknologi Informasi, vol 10(1), pp. 1-18.

[3] Sadoughi F, Ghaderzadeh M, Solimany M, Fein R, 2014. An Intelligent System Based on Back Propagation Neural Network and Particle Swarm Optimization for Detection of Prostate Cancer from Benign Hyperplasia of Prostate. $J$ Health Med Informat, vol 5(3), pp. 1-5.

[4] Linda Deelen, Mauricio Dupleich, Louis Othieno, and Oliver Wakelin.,2003. Leasing untuk Usaha Kecil dan Mikro. Jakarta.

[5] Irvan Muzakkir, Abdul Syukur, and Ika Novita Dewi, 2014. Peningkatan Akurasi Algoritma Backpropagation dengan Seleksi Fitur Particle Swarm Optimization dalam Prediksi Pelanggan Telekomunikasi yang Hilang. Jurnal Pseudocode, vol 1(1), pp. 1-10.

[6] Joko S. Dwi Raharjo, 2013. Model Artificial Neural Network Berbasis Particle Swarm Optimization untuk Prediksi Laju Inflasi. Jurnal Sistem Komputer, vol 3 no. 1, pp. 10-21.

[7] M.F. Andrijasa and Mistianingsih, 2010. Penerapan Jaringan Syaraf Tiruan Untuk Memprediksi Jumlah Pengangguran di Provinsi Kalimantan Timur Dengan Menggunakan Algoritma Pembelajaran

Backpropagation, vol 5 no. 1, pp. 50-54.

[8] R. A. Rachman, D. Syarif, and R. P. Sari, 2012. Analisa dan Penerapan Metode Particle Swarm Optimization Pada Optimasi Penjadwalan Kuliah, vol. 1, pp. 1-10.

[9] Daniel T. Larose, 2006. Data Mining Methods and Models. Hoboken, New Jersey, United State of America : John Wiley \& Sons, Inc.

[10] S. Mohaghegi, Y. Valle, G. K. Venayagamoorthy, and R. G. Harley, 2005. A Comparison Of PSO and Backpropogation For Training RBF Neural, pp. 1-4.

[11] Xiaorong Cheng, Dong Wan, Kun Xie,PSO Algorithm Combined with Neural Network Training Study.

[12] Suyanto, 2010. Algoritma Optimasi Deterministik atau Probabilistik. Yogyakarta.

[13] S. Peters, 2006. Weight Optimization for a Neural Network using Particle Swarm Optimization ( PSO ). 
[14] Florin Gorunescu, 2011. Data Mining Concepts, Models and Techniques, Intelligent Systems Reference Library ed.: Springer-Verlag Berlin Heidelberg.

[15] J. Kennedy and R. C. Eberhart Particle Swarm Optimization In Proceedings Of the 1995
IEEE International Conference on Neural Networks. IEEE Service Center, Piscataway, 1995.

[16] T. Sutojo, S.Si., M.Kom., Edy Mulyanto, S.Si., M.Kom., Dr. Vincent Suhartono, 2011. Kecerdasan Buatan. Semarang. 